\title{
Martel Guylaine : Incarner la politique. La construction de l'image médiatique des femmes et des hommes politiques au Québec
}

Marie Berthoud

\section{(2) OpenEdition}

\section{Journals}

Édition électronique

URL : http://journals.openedition.org/edc/9030

DOI : 10.4000/edc. 9030

ISSN : 2101-0366

\section{Éditeur}

Université de Lille

Édition imprimée

Date de publication : 1 juin 2019

Pagination : 221-224

ISBN : 978-2-917562-21-5

ISSN : $1270-6841$

\section{Référence électronique}

Marie Berthoud, « Martel Guylaine : Incarner la politique. La construction de l'image médiatique des

femmes et des hommes politiques au Québec », Études de communication [En ligne], 52 | 2019, mis en ligne le 01 juin 2019, consulté le 21 janvier 2021. URL : http://journals.openedition.org/edc/9030 ;

DOI : https://doi.org/10.4000/edc.9030

Ce document a été généré automatiquement le 21 janvier 2021.

(c) Tous droits réservés 


\title{
Martel Guylaine : Incarner la politique. La construction de l'image médiatique des femmes et des hommes politiques au Québec
}

\author{
Marie Berthoud
}

1 Dans son ouvrage Incarner la politique. La construction de l'image médiatique des femmes et des hommes politiques au Québec paru en 2018, Guylaine Martel s'intéresse aux personnalités publiques et médiatiques que sont les élus politiques au Québec aujourd'hui. L'objectif de son ouvrage est de contribuer à interroger la façon dont ces élus politiques, femmes et hommes, incarnent la politique et sont présentés comme incarnant la politique à travers les médias aujourd'hui au Québec (p. 5). Il est question dans cette étude d'analyser la façon dont la politique est, à travers les médias, personnalisée, performée, incarnée et même "vedettarisée » par des élus politiques qui, par le rôle qu'ils se composent, participent à construire une certaine image de leur candidature, de ce qu'est un "politicien », du parti qu'il représente et, au-delà, de la politique en général. Les notions de "performance », de processus « d'incarnation » et de « mise en scène » dans les analyses de discours sont mobilisées dans cette étude pour rendre compte de la construction médiatique des figures en politiques comme processus et exercice complexe.

2 L'ouvrage de 177 pages est organisé en quatre chapitres. Le premier chapitre intitulé «L'image médiatique des femmes et des hommes politiques » présente la façon dont les élus politiques doivent composer leurs rôles avec certaines exigences en matière de formats médiatiques tels que par exemple l'incontournable « Débat des chefs », et avec certaines exigences de personnalités telles que le charisme. Le second chapitre, « La construction identitaire des femmes et des hommes politiques " poursuit l'analyse en insistant sur la complexité pour ces élus politiques de se construire une identité à partir de leur vie privée et publique. Le troisième chapitre s'intéresse particulièrement à la «Mise en scène des femmes et des hommes en politiques » et rend compte des 
différents contextes médiatiques (informations, divertissements, entrevues, émissions politiques) avec lesquels doivent composer les élus politiques dans leurs performances communicationnelles. Enfin, le quatrième et dernier chapitre intitulé «La rhétorique des femmes et des hommes politiques » est plus particulièrement axé sur l'analyse des procédés discursifs par lesquels les élus politiques cherchent à construire leur image et à en maitriser la forme. Ces chapitres sont nourris de nombreux exemples et d'études de cas qui viennent aider à la compréhension du processus d'incarnation politique.

Plusieurs points paraissent importants dans cet ouvrage et en font également une approche originale.

4 Tout d'abord, l'ouvrage n'est pas un manuel qui viserait à lister les «bons » ou «mauvais» comportements à suivre en politique. L'auteure l'indique dès son introduction et le lecteur pourra en effet s'apercevoir rapidement que l'enjeu est bien de comprendre ce qui aujourd'hui participe à définir le "politicien ". Autrement dit, loin d'être une construction d'un idéal type d'élus politiques, cet ouvrage tend à interroger le processus de construction médiatique des femmes et des hommes politiques.

Deuxièmement, concernant la méthode d'analyse, Guylaine Martel fait le choix d'étudier les constructions discursives des propres élus politiques et ainsi d'analyser leur image médiatique telle qu'eux-mêmes la construisent. L'auteure fait le choix de mener cette analyse de discours à partir de plus de 500 heures d'enregistrements de talk-show, émissions politiques ou interviews. Les nombreux exemples qui nourrissent cet ouvrage permettent de saisir cette construction discursive et la façon dont des élus politiques se construisent eux-mêmes une image et un rôle à travers les médias.

Troisièmement, cette construction est, tout au long de l'ouvrage, présentée comme dynamique et l'objet de négociations perpétuelles entre différents acteurs. En effet, la construction des rôles est toujours présentée comme un processus auquel participent les élus politiques, mais également les médias, les journalistes et les citoyens qui jouent dès lors un rôle dans la construction et la reconnaissance de l'incarnation politique. À cet égard, Guylaine Martel n'oublie pas de rendre compte de la manière dont l'évolution des dispositifs médiatiques et la médiatisation croissante des élus politiques ont elles aussi contribué à transformer les rapports entre la sphère politique, journalistique et citoyenne. Ainsi, tout en étudiant la manière dont les élus politiques se construisent une image dans les médias, Guylaine Martel étudie également ce que les médias font aux élus politiques.

7 Enfin, au-delà de la problématique générale qui tend à saisir ce qu'est aujourd'hui un politicien au Québec (p 5), il nous semble que cette étude permet d'interroger de manière générale ce qu'est la politique, au regard des personnalités qui en sont les acteurs et de leurs rôles médiatiques. Loin de résumer les "politiciens » à des figures médiatiques, Guylaine Martel montre en revanche à quel point leurs rôles sont sans cesse renégociés en fonction des contextes et de leurs réappropriations. Ce « jeu », au sens à la fois de mise en scène, mais aussi de processus dynamique, nous parait poursuivre les études info-communicationnelles qui ont été menées à propos de la politique à travers les médias de façon tout à fait actuelle. 


\section{AUTEUR}

\section{MARIE BERTHOUD}

Univ. Lille, EA 4073 - GERiiCO -

Groupement d'Études et de Recherche

Interdisciplinaire en Information

et Communication, F-59000 Lille, France

marie.berthoud@univ-lille.frMartel G. (2018). Incarner la politique. La construction de l'image médiatique des femmes et des hommes politiques au Québec, Québec, Presses Universitaires de Laval 